Научная статья

УДК 371.123

DOI: $10.18101 / 2307-3330-2021-3-48-52$

\title{
МУЛЬТИЗАДАЧНОСТЬ СОВРЕМЕННОГО ПЕДАГОГА: МИФ ИЛИ РЕАЛЬНОСТЬ
}

\author{
(C) Сидорова Татьяна Владимировна \\ кандидат педагогических наук, доцент, \\ Бурятский государственный университет имени Доржи Банзарова \\ Россия, 670000, г. Улан-Удэ, ул. Смолина, 24a \\ botkina@yandex.ru
}

\begin{abstract}
Аннотация. Педагог XXI в. вынужден работать в условиях информационной перегрузки, переключаться с одного дела на другое оперативно и при этом оказывать качественную образовательную услугу в условиях дистанционного обучения. Список профессиональных компетенций молодого учителя пополняется новыми социальнопсихологическими характеристиками, среди которых умение работать в условиях многозадачности. В статье дается анализ данного феномена с точки зрения его актуальности в педагогической среде. Проведенное автором исследование показало, что ролевой репертуар современного педагога меняется: учитель становится не просто транслятором знаний, а проводником в информационном пространстве, комментатором, навигатором в образовательном контенте. Происходит трансформация привычных форм взаимодействия как с учениками, так и с их семьями в офлайн и в онлайн. К работе в режиме мультизадачности необходимо готовить будущих педагогов в стенах педагогического вуза.
\end{abstract}

Ключевые слова: многозадачность, цифровое образование, информационные перегрузки, молодой педагог.

\section{Для цитирования}

Сидорова Т. В. Мультизадачность современного педагога: миф или реальность // Вестник Бурятского государственного университета. Образование. Личность. Общество. 2021. № 3. С. 48-52.

Школьное образование выходит на совершенно новый уровень, открывая для себя как плюсы, так и минусы дистанционного обучения. Многим учителям не просто справиться с такими стремительными переменами и принять новые реалии сферы образования. Как показывает практика и опросы школьных педагогов [6], успешным становится тот специалист, который умеет работать в режиме многозадачности. Действительно ли многозадачность помогает молодым педагогам быстрее адаптироваться к непростым условиям труда в современную эпоху цифровой реальности и неопределенности?

Специалисты Американской психологической ассоциации дали следующее определение многозадачности, которое считается на сегодняшний момент наиболее популярным: многозадачность (от англ. Multitasking) — «это тенденция к выполнению двух задач одновременно, быстрому переключению между не- 
сколькими задачами или выполнению двух и более задач в быстрой последовательности» [9].

Ученые изучают многозадачность уже около 25 лет. Большинство исследований демонстрирует, что так называемый мультитаскинг снижает эффективность и производительность. Это доказали ученые из Университета Стэнфорда и Университета Сассекса [10].

Социальный эксперимент «Инфомания», который провел психолог Гленн Уилсон из Института психиатрии Лондонского университета [2], показал, что у людей, которые пытаются выполнить интеллектуальную работу в режиме многозадачности, наблюдается заметный спад показателей IQ. По мнению доктора философских наук Е. В. Поликарповой, главный изъян использования режима многозадачности в образовательных целях заключается в том, что он не способствует формированию личностных знаний, тормозит развитие осмысляющего мышления, следовательно, препятствует актуализации творческого потенциала, духовному обогащению личности, невозможному без сформированной потребности в серьезном чтении, без глубокой вовлеченности в процесс познания [4].

Тем не менее многозадачность как качество личности становится неотъемлемым требованием успешного специалиста в любой сфере деятельности, ибо те информационные перегрузки, с которыми сталкивается человечество, не оставляет выбора. Более того, если обратиться к описаниям различных вакансий, то можно встретить требование «уметь действовать в условиях многозадачности», многие руководители считают это умение одним из ключевых для современного специалиста любой сферы.

Информационный взрыв [7], который кардинально изменил пространство нашей жизни, систему отношений и общения, трансформировал реальность, и сегодня все привычные слова мы используем с прилагательным «цифровая» революция, эпоха, экономика, личность, образование и т. п. Трансформируются ли требования к современному педагогу? Ответ однозначный — да.

В связи с доступностью знаний, потерей их субъективной ценности роль педагога значительно меняется. Современный учитель не просто носитель и транслятор знаний, он выступает одновременно организатором и мотиватором обучения. Проведенное нами анкетирование, в котором приняли участие 300 педагогов с различным педагогическим стажем (от 1 года до 35 лет работы), выявило изменения в ролевом репертуаре современного педагога (результаты отражены в диаграмме).

Кроме того, учитель становится проводником в информационном пространстве, комментатором, навигатором в образовательном контенте, помогающим обучающимся ориентироваться в информационном потоке и систематизировать уже найденную ими информацию [8, с. 40]. Соответственно, и профессиональные компетенции педагога требуют модификации и трансформации.

От молодого школьного учителя ждут энергичности, образованности, легкой адаптации к изменениям, гибкости, а также глубоких знаний своего предмета и желания передать эти знания детям различными интерактивными способами, в том числе цифровыми. Молодого учителя, недавно закончившего вуз, ждет мно- 
го сложной, но в то же время интересной работы в школе, а главная его задача найти подход к детям, заинтересовать, увлечь своим предметом и в конечном счете воспитать достойного гражданина и гармоничного человека.

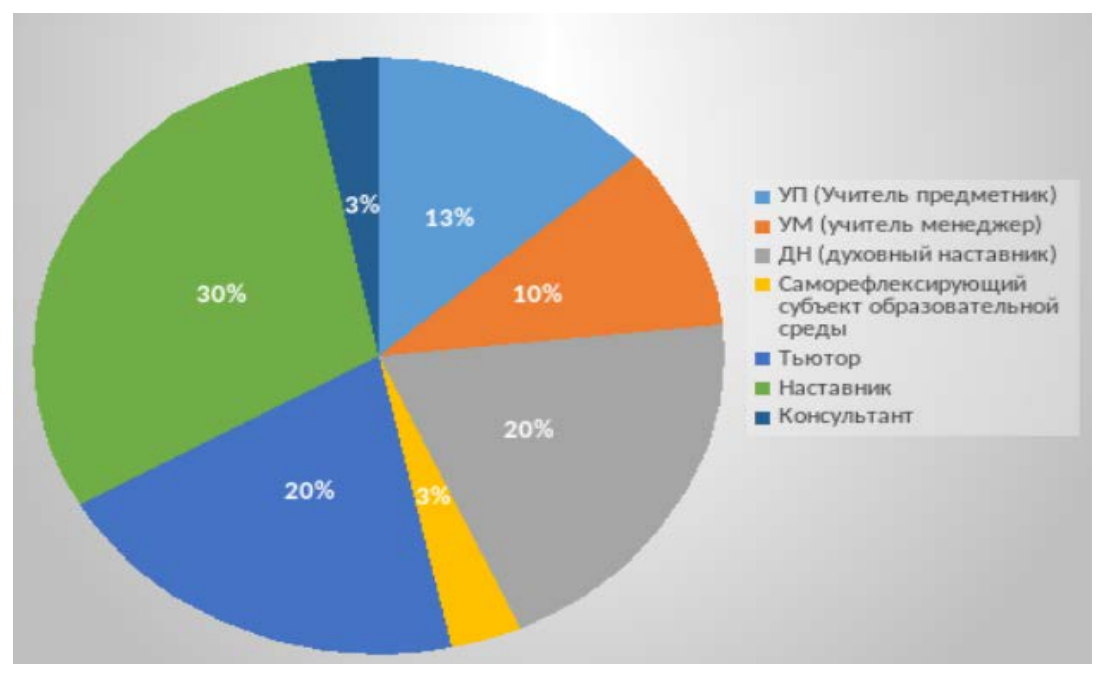

Рис. 1. Роль педагога в отношении учеников

Найти общий язык со школьниками поколения Альфа молодым педагогам, относящимся к поколению $\mathrm{Z}$ или $\mathrm{Y}$ проще, так как между ними разница всего в 10-15 лет. Психологические исследования различных особенностей развития современных школьников $[1,4]$ позволяют определить принципиальные особенности, характеризующие современных учеников, среди которых легкость восприятия информации, мобильность в освоении техники и различных технических приспособлений, прагматизм, отстраненность от проблем реального мира, недостаточный самоконтроль и др. Современные дети легко переключаются с одной задачи на другую и могут заниматься двумя делами одновременно, например, делать уроки и смотреть видеоролики в тик-токе.

Наблюдения за молодыми педагогами на педагогическом совете показали, что они одновременно делают несколько дел: слушают директора, проверяют тетради учеников и отвечают другу в мессенджерах. Эффективность данных действий еще предстоит изучить в экспериментальных исследованиях, однако сегодня нельзя не сказать о колоссальной нагрузке, с которой приходится иметь дело педагогу в цифровую эпоху. Он, как и любой человек, неизбежно сталкивается с информационной перегрузкой. Многие исследователи делают вывод, что многозадачность - это такая же способность, как писать, читать или общаться с людьми. Она настолько фундаментальна и естественна, что воспринимается как нечто само собой разумеющееся.

Феномен многозадачности относится к компьютерам, способным выполнять несколько разных операций одновременно. Однако на самом деле компьютеры 
лишь создают иллюзию многозадачности, а в действительности быстро переключаются между задачами. То же самое можно сказать и о людях, только компьютеры переключаются значительно быстрее, и их не мучает чувство вины от невыполненных задач.

Учитель часто чувствует себя загруженным делами, ведь у него практически не остается личного «своего» времени: классному руководителю в любое время могут написать родители учеников или позвонить директор поздно вечером, чтобы обсудить какое-либо мероприятие. $\mathrm{C}$ развитием информационнокоммуникационных технологий стираются временные и пространственные границы, учитель доступен практически круглосуточно [5].

Цифровизация образования и опосредованное общение - это не столько электронные социальные, образовательные ресурсы и информационнокоммуникационные технологии, сколько пути изменения привычных форм взаимодействия с семьями учеников как в офлайн, так и в онлайн [3]. В связи с этим быстрое переключение из онлайн-общения в офлайн, заполнение электронного и простого журнала одновременно, ведение дистанционных и «живых» занятий поочередно становятся реалиями современной школы, к которым надо готовить молодых педагогов в стенах педагогического вуза. Последствия работы в многозадачном режиме как для самого педагога, так и для образовательного процесса в целом покажут пролонгированные педагогические исследования.

Литературы

1. Авдулова Т. П. Психология подросткового возраста. Москва: Academia, 2015. 288 с. Текст: непосредственный.

2. Интервью Гленна Уилсона. URL: http://www.drglennwilson.com/links.html (дата обращения: 20.09.2021). Текст: электронный.

3. Петраш Е. А., Сидорова Т. В. Виртуальные формы взаимодействия педагога с родителями в современной образовательной организации // Педагогика. Вопросы теории и практики. 2020. Т. 5, вып. 5. С. 604-609. Текст: непосредственный.

4. Поликарпова Е. В. Цифровизация образования: миф многозадачности // Манускрипт. 2020. Т. 13, вып. 10. С. 197-203. Текст: непосредственный.

5. Сидорова Т. В. Многозадачность как социально-психологическая характеристика современного учителя // Вестник Бурятского государственного университета. Образование. Личность. Общество. 2020. Вып. 3. С. 60-64. Текст: непосредственный.

6. Сильченкова С. В., Ермолаева Е. Б. Управление профессиональными ролями учителей в условиях многозадачности их деятельности // Актуальные проблемы теории и практики управления. Курск, 2019. С. 304-307. Текст: непосредственный.

7. Шнейдер Л. Б. Вчера, сегодня, завтра: от «кликового» к клиповому и далее к чиповому мышлению // Цифровое общество в культурно-исторической парадигме. Москва, 2018. С. 198-203. Текст: непосредственный.

8. Яницкий М. С. Психологические аспекты цифрового образования // Профессиональное образование в России и за рубежом. 2019. № 2. С. 38-44. Текст: непосредственный.

9. Miller J., Mittelstädt V. Separating limits on preparation versus online processing in multitasking paradigms: evidence for resource models // Journal of experimental Psychology: Human Perception and Performance. 2017. Vol. 43, no. 1. P. 89-102. 
10.Nass C. Media multitaskers pay mental price, Stanford study shows. URL: https://news.stanford.edu/news/2009/august24/multitask-research-study-082409.html (date of the application: 20.09.2021).

Статья поступила в редакиию 18.11.2021; одобрена после рецензирования 22.11.2021; принята к публикациии 07.12.2021.

\section{MULTITASKING OF A MODERN TEACHER: MYTH OR REALITY}

\section{Tatiana V. Sidorova}

candidate of pedagogical sciences, associate professor

Dorzhi Banzarov Buryat State University

24a Smolina St. Ulan-Ude, 670000, Russia

botkina@yandex.ru

The teacher of the XXI century is forced to work in conditions of information overload, quickly switch from one case to another and at the same time should provide a high-quality educational service in the context of distance learning. The list of professional competencies of a young teacher is being replenished with new socio-psychological characteristics, including the ability to work in a multitasking environment. The article analyzes this phenomenon from the point of view of its relevance in the educational environment. The research carried out by the author has shown that the role-playing repertoire of the modern teacher is changing: the teacher becomes not just a translator of knowledge, but a conductor in the information space, a commentator, a navigator in educational content. There is a transformation of the usual forms of interaction both with students and with their families, both offline and online. It is necessary to prepare future teachers for work in multitasking mode within the walls of a pedagogical university.

Keywords: multitasking, digital education, information overload, young teacher.

The article was submitted 18.11.2021; approved after reviewing 22.11.2021; accepted for publication 07.12.2021. 